\title{
sciendo
}

\section{Remittance in Niger: effects on economic growth and on migrants' left behind}

\author{
Issoufou Oumarou \\ Université de Tahoua, Tahoua, Niger \\ oumar1911@yahoo.com
}

\begin{abstract}
Remittances have long been an important source of revenue for many people in the Republic of Niger. In order to fight poverty, young people choose to migrate. In 2019 , a total of 293 million U.S. dollars was sent by migrants to their relatives in Niger; that is $3 \%$ of Niger Gross Domestic Product (GDP). The objective of this study is to analyze the effects of remittances on economic growth in Niger and the significance of its contribution in improving the living condition of migrants' left behind families. The study applies a three-step econometric procedure followed by a survey on the usage of the remittances in the city of Tahoua (Republic of Niger). The study also performed some tests on the residuals for the accuracy of the prediction of the model. The empirical results showed no long run relationship between remittances, economic growth and gross fixed capital formation in Niger. However, in the shortrun, the study revealed the existence of causal effect between remittances and economic growth. On the other hand, the results of the conducted survey in the city of Tahoua showed that $45.7 \%$ of the received remittance is used in food expenditure, $19.3 \%$ in education expenditure, $10.36 \%$ in health expenditure and $5.4 \%$ is allocated to house rent. The survey also revealed the importance of the remittances for the left behind. It indicates that $14 \%$ of the respondent left behind wish to see another family member engage in migration.
\end{abstract}

Keywords: economic growth, left behind, Niger, remittance, Tahoua.

JEL classification: C32, F24, F43, O15.

DOI: 10.2478/crebss-2021-0005

Received: May 11, 2020

Accepted: March 17, 2021

\section{Introduction}

Commonly defined as a certain quantity of money sent regularly to families based in home countries, remittances are an important part of the current overall economy. In 2019, an estimated 573 billion U.S. dollars was sent by migrants to their home countries (World Bank, 2019). In 2019, a total of 293 million U.S. dollars was sent by migrants to their relatives in Niger (World Bank, 2019), that is $3 \%$ of Niger GDP.

The present study aimed firstly to examine the significance of remittances on economic growth in Niger using time series analysis and secondly to investigate through a survey, the usage of the received remittances in the city of Tahoua (Republic of Niger) known nationwide with its long history of labour migration. In 
order to reach its objective the study used various time series econometric techniques such as the Phillips and Peron (PP) unit root test, Engle-Granger cointegration test and Vector autoregressive (VAR) procedure. The study also performed some diagnostic tests on the residuals such as serial correlation, heteroskedasticity and normality for the accuracy of the prediction of the model.

The present article contributes towards the ongoing debates on the impact of remittances on economic growth of the migrants' country of origin. The distinction of this study from other studies on remittances in developing countries is the fact that there are not adequate writings on remittances linking the country of Niger. The study therefore also intends to fill in this existing gap.

The paper is organized as follows: The first part presents a review of the literature and the previous empirical research relating remittances with economic growth. The second part of the paper describes the research variables, the sources of data and the methodology used in the study. The third part of the paper presents the econometric tests results and discussions. The fourth part of the paper presents the conclusion of the study, while the fifth part lists the literature used.

\section{Literature review}

Anetor (2019) examine the relationship between remittances, financial sector development, and economic growth in Nigeria over the period 1981 to 2017. The author used the autoregressive distributed lag (ARDL) model to analyze the long-run and short-run relationships between the variables. The study results showed that the variables are bound together in the long-run and remittances have a negative and significant effect on economic growth both in the long-run and short-run.

Eric and Mohamed (2019) in their article used time series analysis to investigate the relationship between migrant remittances and economic growth. They used data of four countries: Bangladesh, India, Pakistan and the Philippines from the period covering 1977 and 2015. They found evidence of causality between remittances and economic growth in Bangladesh, Pakistan and the Philippines.

Juthathip and Archanun (2019) in their article used data for the period covering 1993 to 2013 to examine the impact of remittances on economic growth in developing countries in Asia and the Pacific. Their results showed that remittances generate negative and significant impacts on economic growth if they reach 10 percent of GDP or higher. Their research also revealed that a remittances-to-GDP ratio of below 10 percent could impact growth negatively, but the effect is statistically insignificant.

Manuel and Mariellen (2019) in their article investigated the impact of migrants' remittances and investment on rural youth. They found that remittances positively contribute to the sustainable economic development of rural youth in their countries of origin.

Annie and Nicole (2018) in their article investigated the connection between international migration, remittances and human capital investment in Kenya. They used household data from the 2009 of the Kenyan' Migration Household Survey to check their hypothesis and reveal a positive and significant link between the amount of international remittances a household receives and the amount of expenditures allocated to education. They also measured various robustness checks and fond that their results hold up to various specifications, including instrumental variable approach.

Adenutsi (2010) in his paper examined the macroeconomic impact of inward international remittances on human-centred development in 15 Sub-Saharan African countries. The author used fixed-effects balanced panel data estimation 
procedure on data covering the period from 1987 to 2007. The study results revealed that international remittances positively impact human capital in the long-run.

Hillel and Frédéric (2004) in their article reviewed the recent theoretical and empirical economic literature on migrants' remittances. They showed that models based on different motives share numerous common predictions, making it difficult to realize truly discriminative tests in the lack of sufficiently detailed data on migrants and receiving households' distinctiveness and on the timing of remittances.

\section{Research data and methodology Research data}

In order to analyze the contribution of remittances in the economic development of Niger and access to the contribution of the remittances on local development of the city of Tahoua, the present study combines time series econometric analysis and a survey on the usage of the remittances by the migrants left behind in the city of Tahoua in the Republic of Niger.

The data used for the econometric analysis are annual data of Niger obtained from the International monetary fund (IMF). The data cover the period from 1980 to 2019. All data are given in logarithms and the variables are expressed with the letter $L$ at the beginning. The study used Gross Domestic Product (GDP) as proxy of economic growth. GDP is taken as dependent variable. Remittance and Gross fixed capital formation (GFCF) are used as independent variables. In this study remittance is the interest variable. Table 1 provides the descriptive statistics of the variables.

Table 1 Descriptive statistics of the research variables

\begin{tabular}{|c|c|c|c|c|c|c|}
\hline Variables & Obs. & Mean & Median & Maximum & Minimum & Std. Dev. \\
\hline Lgdp & 40 & 21.85833 & 21.57191 & 22.96838 & 21.08831 & 0.601896 \\
Lrem & 40 & 17.27597 & 16.75330 & 19.48446 & 15.31916 & 1.298973 \\
Lgfcf & 40 & 20.06277 & 19.53621 & 21.83677 & 18.50429 & 1.145475 \\
\hline
\end{tabular}

Source: Authors' calculation based on data from the International Monetary fund.

The households considered for the survey are 50 households having at least one migrant in the family. The study considered two types of migrations: cross-border migration and regional migration. Table 2 gives the socio-demographic profile of responding left behind migrant families.

Table 2 Socio-demographic profile of responding left behind migrant families

\begin{tabular}{|c|c|c|c|c|c|}
\hline Variables & Obs. & Average & Min & Max & Mode \\
\hline Age of the migrant household responsible & 50 & 27,3 & 19 & 42 & 26 \\
Family size & 50 & 4,44 & 2 & 8 & 4 \\
Yearly received remittance (USD) & 50 & $\$ 1785.6$ & $\$ 1000$ & $\$ 3600$ & $\$ 1600$ \\
\hline
\end{tabular}

Source: Author's calculation based on data from the survey.

Table 2 shows that the average age of the responsible of the left behind migrants' family is 27.3 years and the average yearly received remittance is US dollars $\$ 1785.6$. The table also shows that the average size of receiving remittance' family is 4.44 .

\section{Methodology}

The current paper follows a three-step procedure. First, time series Phillips and Peron unit root test was applied for stationarity to avoid spurious regression. In second step, the study used Engle-Granger two steps cointegration test for testing the presence of cointegration relationship between the variables. If series are cointegrated, there is a 
long run relationship among the variables. In third step, if the series are cointegrated of the same order, the vector error-correction model (VECM) is applied. If the series are not cointegrated based on the findings of step 2, the vector autoregression (VAR) method is applied. Finally, further residual tests including serial correlation and heteroskedasticity tests were performed for the accuracy of the prediction of the model. For testing the significance of the remittance on economic growth in Niger, the study used a general model given by the following equation:

$$
L Y_{t}=\beta_{0}+\beta_{1} \text { Lrem }_{t}+\sum_{i=2}^{n} \beta_{i} X_{i t}+\mu_{t}
$$

where: $L$ represent natural logarithm, $Y$ stands for Gross domestic product, rem stands for remittance, $X$ are complementary series for growth (in our study only Gross fixed capital formation is represented by the term) and $u$ represents the error term. The equation for this study becomes then:

$$
L g d p_{t}=\beta_{0}+\beta_{1} \operatorname{Lrem}_{t}+\beta_{2} L g f c f_{t}+\mu_{t}
$$

Following the Engle-Granger two steps approach, the residual series generated from the following equation is tested for presence of cointegration:

$$
\widehat{u_{t}}=L g d p_{t}-\left(\beta_{0}+\beta_{1} \operatorname{Lrem}_{t}+\beta_{2} L g f c f_{t}\right)
$$

Finally, further residual tests including serial correlation and heteroskedasticity tests were performed for the accuracy of prediction of the model.

\section{Results and discussions \\ Unit root and stationary tests results}

Before conducting the unit root and the stationary tests, the study begins by determining the optimal lag to use in the model. EViews software is used to determine the optimal lag to use in the model. The software recommends choosing the optimal lag according to the suggestion of Akaike information criterion (AIC) or Schwarz information criterion (SIC). The optimal choice is obtained by choosing the lag number suggested by the information criterion with the lower value between the AIC and SIC. The value provided by the AIC $(-1,428649)$ is lower than the one provided by the SIC $(-0,523667)$. Therefore, we conclude based on this output that the lag selection must be based on the AIC. The optimal lag selected for the model by the $\mathrm{AIC}$ is $\mathrm{k}=2$.

The Augmented Dickey-Fuller (ADF) test is used for testing the presence of unit root in the variables at series level and at series' first differences. The tests results are given bellow in Table 3 and Table 4. The ADF test null hypothesis is stated as follow: "Series has a unit root". The test equation includes constant without trend. The test is conducted at $5 \%$ significance level.

Table 3 Augmented Dickey-Fuller (ADF) test at series level

\begin{tabular}{|c|c|c|c|}
\hline Variables & Number of lags & ADF test statistic & (p_value) \\
\hline Lgdp & 2 & 0.232790 & $(0.9711)$ \\
Lrem & 2 & -0.246993 & $(0.9232)$ \\
Lgfcf & 2 & -1.092535 & $(0.7085)$ \\
\hline
\end{tabular}

Source: Author's calculation.

Table 3 shows the ADF unit root test on series level. The $5 \%$ significance level ADF test critical value at series level as provided by the econometric software package (Eview 7) is -2.943427. The ADF test statistics for all the variables (Lgdp, Lrem, Lgfcf) are higher than the $5 \%$ critical value which indicates that the null hypothesis can't be rejected. Hence all the series have unit root. 
Table 4 Augmented Dickey-Fuller (ADF) test at series' first differences

\begin{tabular}{|c|c|c|c|}
\hline Variables & Number of lags & ADF test statistic & (p_value) \\
\hline Lgdp & 2 & $-3.507196^{*}$ & $(0.0135)$ \\
Lrem & 2 & $-3.621330^{*}$ & $(0.0101)$ \\
Lgfcf & 2 & $-3.346362^{*}$ & $(0.0200)$ \\
\hline
\end{tabular}

Source: Author's calculation.

Table 4 shows the ADF unit root test on series first differences. The $5 \%$ significance level ADF test critical value at series first difference is -2.945842 . The ADF test statistics for all the variables (Lgdp, Lrem, Lgfcf) are lower than the $5 \%$ critical value and the p_values are less than 0.05 which indicates rejection of the null hypothesis. Hence all the series do not have unit root.

According to the ADF unit root test results, the null hypothesis can't be rejected at $5 \%$ significance level for all the variables at series level. However, the null hypothesis is rejected at $5 \%$ significance level for all the variables at series' first differences. Therefore all the variables are integrated of order one I(1).

After the Augmented Dickey-Fuller (ADF) test, a confirmatory Kwiatkowski-PhilipsSchmidt-Shin (KPSS) stationary test is conducted on the variables under study. The null hypothesis of the KPSS test is stated as follow: "The series is stationary". The KPSS stationary test result is given in Table 5.

Table 5 Kwiatkowski-Philips-Schmidt-Shin (KPSS) test at series level

\begin{tabular}{|c|c|c|c|c|}
\hline Variables & KPSS test statistics & $1 \%$ CV & $5 \%$ CV & $10 \%$ CV \\
\hline Lgdp & $0.63965^{*}$ & 0.73900 & 0.46300 & 0.34700 \\
Lrem & $0.68563^{*}$ & 0.73900 & 0.46300 & 0.34700 \\
Lgfcf & $0.58320^{*}$ & 0.73900 & 0.46300 & 0.34700 \\
\hline
\end{tabular}

Source: Author's calculation

Table 5 shows the KPSS stationary test results at series level. The KPSS test statistics for all the three variables in the study are greater than the $5 \%$ critical value, which indicates rejection of the null hypothesis. Hence all the three series are not stationary at their levels.

Table 6 Kwiatkowski-Philips-Schmidt-Shin (KPSS) test at series first differences

\begin{tabular}{|c|c|c|c|c|}
\hline Variables & KPSS test statistics & $1 \%$ CV & $5 \%$ CV & $10 \%$ CV \\
\hline Lgdp & $0.45829^{*}$ & 0.73900 & 0.46300 & 0.34700 \\
Lrem & $0.14017^{*}$ & 0.73900 & 0.46300 & 0.34700 \\
Lgfcf & $0.35629^{*}$ & 0.73900 & 0.46300 & 0.34700 \\
\hline
\end{tabular}

Source: Author's calculation

Table 6 shows the KPSS stationary test results at series first differences. The KPSS test statistics for all the three variables in the study are lower than the $5 \%$ critical value, which indicates failure to reject of the null hypothesis. Hence all the three series are stationary at their first differences.

The Augmented Dickey-Fuller (ADF) test results are confirmed by the KPSS stationary tests. Hence all the series (Lgdp, Lrem and Lgfcf) are non-stationary at their level but become stationary in their first differences. The 3 variables used in the study are therefore integrated of order one I(1).

\section{Engle-Granger cointegration test results}

Following the Engle-Granger two steps approach, residual series generated from equation (3) is tested for cointegration in the model. The Augmented Dickey-Fuller 
test is applied for testing the presence of unit root in the residual series. The test is conducted on series level at $5 \%$ significance level. The test result is given bellow in Table 7.

Table 7 Engle-Granger cointegration test result

\begin{tabular}{|c|c|c|c|}
\hline Variable & ADF test statistic & (p_value) & 5\% Critical Value \\
\hline Model residual & -1.393007 & $(0.1494)$ & -1.950117 \\
\hline
\end{tabular}

Source: Author's calculation

Table 7 shows the ADF unit root test result on the residuals. The ADF test statistic is greater than the $5 \%$ critical value and the probability value is greater than 0.05 ( $p>0.05)$ which indicates that the null hypothesis can't be rejected. Hence the residuals series has a unit root. That means no cointegration in the model. Therefore, according to the Engle-Granger two steps test result the variables are not cointegrated. There is no long-term equilibrium relationship between economic growth, remittance and gross fixed capital formation.

\section{Vector autoregressive estimate results}

Since the variables in the study are not cointegrated only short-run model, which is vector autoregressive (VAR) is estimated. Considering that the optimal lag to use in the model as suggested by the information criterion, the following $V A R$ equations are estimated:

$$
\begin{aligned}
& \operatorname{Lgdp}_{\mathrm{t}}=\alpha_{11}+\sum_{\mathrm{i}=1}^{2} \beta_{\mathrm{i} 1} \operatorname{Lgdp}_{\mathrm{t}-\mathrm{i}}+\sum_{\mathrm{j}=1}^{2} \gamma_{\mathrm{j} 1} \operatorname{Lrem}_{\mathrm{t}-\mathrm{j}}+\sum_{\mathrm{k}=1}^{2} \delta_{\mathrm{k} 1} \operatorname{Lgfcf}_{\mathrm{t}-\mathrm{k}}+\mu_{1 \mathrm{t}} \\
& \operatorname{Lrem}_{\mathrm{t}}=\alpha_{12}+\sum_{\mathrm{i}=1}^{2} \beta_{\mathrm{i} 2} \operatorname{Lgdp}_{\mathrm{t}-\mathrm{i}}+\sum_{\mathrm{j}=1}^{2} \gamma_{\mathrm{j} 2} \operatorname{Lrem}_{\mathrm{t}-\mathrm{j}}+\sum_{\mathrm{k}=1}^{2} \delta_{\mathrm{k} 2} \operatorname{Lgfcf}_{\mathrm{t}-\mathrm{k}}+\mu_{2 \mathrm{t}} \\
& \operatorname{Lgfcf}_{\mathrm{t}}=\alpha_{13}+\sum_{\mathrm{i}=1}^{2} \beta_{\mathrm{i} 3} \operatorname{Lgdp}_{\mathrm{t}-\mathrm{i}}+\sum_{\mathrm{j}=1}^{2} \gamma_{\mathrm{j} 3} \operatorname{Lrem}_{\mathrm{t}-\mathrm{j}}+\sum_{\mathrm{k}=1}^{2} \delta_{\mathrm{k} 3} \operatorname{Lgfcf}_{\mathrm{t}-\mathrm{k}}+\mu_{3 \mathrm{t}}
\end{aligned}
$$

where: $\alpha_{1 i}$ are intercepts; $\beta_{1 i}, \gamma_{1 i}$ and $\delta_{1 i}$ are short-run dynamic coefficients of the model and $\mu_{i t}$ are residuals in the equations (with $i=1,2,3$ ).

After the VAR estimation, Granger-Wald causality test on lagged explanatory variables is applied to check the causality. The null hypothesis of the Granger-Wald causality test is stated as follow: "All the lag coefficient of the independent variable do not cause the dependent variable against the alternative that these lag coefficient cause the dependent variable. Table 8 and Table 9 give respectively the VAR estimation results and the Granger-Wald causality test results.

Table 8 Vector autoregressive estimation results

\begin{tabular}{|c|c|c|c|}
\hline Variables lags & Lgdp & Lrem & Lgfcf \\
\hline Lgdp(-1) & 0.890507 & -0.104555 & 0.116509 \\
& {$[3.66570]$} & {$[-0.13489]$} & {$[0.25941]$} \\
\hline \multirow{2}{*}{ Lgdp(-2) } & -0.441590 & 0.200131 & -0.527597 \\
& {$[-1.77575]$} & {$[0.25222]$} & {$[-1.14753]$} \\
\hline \multirow{2}{*}{ Lrem(-1) } & 0.006982 & 0.859462 & 0.140220 \\
& {$[0.11565]$} & {$[4.46160]$} & {$[1.25621]$} \\
\hline \multirow{2}{*}{ Lrem(-2) } & 0.135521 & -0.205645 & 0.161496 \\
& {$[2.08424]$} & {$[-0.99122]$} & {$[1.34339]$} \\
\hline \multirow{2}{*}{ Lcfcf(-1) } & 0.144636 & 0.781235 & 1.052412 \\
& {$[1.15778]$} & {$[1.95992]$} & {$[4.55652]$} \\
\hline \multirow{2}{*}{ Lcff(-2) } & -0.010157 & -0.481336 & -0.173279 \\
& {$[-0.08534]$} & {$[-1.26756]$} & {$[-0.78750]$} \\
\hline C & 6.917888 & -2.060215 & 6.223256 \\
& {$[2.80297]$} & {$[-0.26162]$} & {$[1.36383]$} \\
\hline
\end{tabular}

Source: Author's calculation 
Table 8 shows the vector autoregressive estimation result. The t-statistics are given in parentheses. Using t-statistic analysis, when Gross domestic product (Lgdp) is used as dependent variable, it can be seen that the second lag of Lrem coefficient (2.08424) is significant. Hence is can be concluded that remittance has a causal effect on Gross domestic product in the short-run. When remittance (Lrem) is used as dependent variable, it can be seen that the second lag of Lgfcf coefficient (1.95992) is weakly significant. Hence is can be concluded that Gross fixed capital formation (Lgfcf) has a weak causal effect on remittance in the short-run.

Table 9 Granger-Wald causality test result

\begin{tabular}{|c|c|c|c|}
\hline Dependent variables & Independent variables & Chi-square & Probability value \\
\hline Lgdp & Lrem & $7.616098^{*}$ & 0.0222 \\
& Lgfcf & 3.055257 & 0.2170 \\
\hline Lrem & Lgdp & 0.066077 & 0.9675 \\
& Lgfcf & 4.017568 & 0.1342 \\
\hline Lgfcf & Lgdp & $8.970568^{*}$ & 0.0113 \\
& Lrem & 1.818604 & 0.4028 \\
\hline
\end{tabular}

Source: Author's calculation.

Table 9 shows Granger-Wald causality test result. The test result showed that when gross domestic product (Lgdp) is used as dependent variable, the null hypothesis of no causal effect is rejected at $5 \%$ significance level for remittance as the probability value $(p=0.0222)$ is less than $0.05(p<0.05)$. This indicates that remittance has a causal effect on gross domestic product in the short-run. When gross fixed capital formation (Lgfcf) is used as dependent variable, the null hypothesis is rejected at $5 \%$ significance level for remittance as the probability value $(p=0.0113)$ is less than 0.05 $(p<0.05)$. This indicates that remittance has a causal effect on gross fixed capital formation in the short-run.

The t-statistic test results are confirmed by the Granger-Wald causality test. Hence it can be concluded that remittance has a causal effect on economic growth and on gross fixed capital formation in Niger in the short-run.

\section{Diagnostic tests on residuals results}

In order to check the reliability of the estimates, some diagnostic tests are conducted on the residuals. Table 10, 11 and 12 give the diagnostic tests on residuals including respectively the autocorrelation, the normality and heteroskedasticity test.

Table 10 Residuals autocorrelation test result

\begin{tabular}{|c|c|c|}
\hline LM Statistic & Test Statistic & Probability value \\
\hline Lag 1 & 18.19389 & 0.0730 \\
Lag 2 & 16.92128 & 0.0680 \\
\hline
\end{tabular}

Source: Author's calculation.

Table 10 shows that the LM statistic for both lag 1 and lags 2 have their tests probability values respectively 0.0730 and 0.0680 . Theses probability values are greater than 0.05. This indicates that the null hypothesis that states that there is no serial correlation among residuals can't be rejected. Hence the residuals are not correlated.

Table 11 shows the residuals normality test result. Looking at Jarque-Bera normality test result, the evidence of normality in the 3 series can't be rejected. Hence the residuals are normally distributed. 
Table 11 Residuals normality test result

\begin{tabular}{|c|c|c|}
\hline Variables & Jarque-Bera statistics & Probability value \\
\hline Lgdp & 1.899004 & 0.3869 \\
Lrem & 0.470588 & 0.7903 \\
Lgfcf & 1.606576 & 0.4479 \\
\hline
\end{tabular}

Source: Author's calculation.

Table 12 Residuals heteroskedasticity test result

Source: Author's calculation.

63.19885

Probability value

\begin{tabular}{|c|c|}
\hline Chi-square & Probability value \\
\hline 63.19885 & 0.7610 \\
\hline
\end{tabular}

Table 12 shows the residual heteroskedasticity test result. The null hypothesis of no heteroskedasticity in the residuals can't be rejected. The residuals are therefore homoskedastics. The diagnostic tests on the residuals showed that the estimates are reliable. That indicates that our model is good.

\section{Survey results}

The survey on the migrants' left behind family investigates the usage of the remittances sent by the migrant and the incentives of the family to encourage another family member for migration. The survey results on remittances usage are provided below in figure 1 .

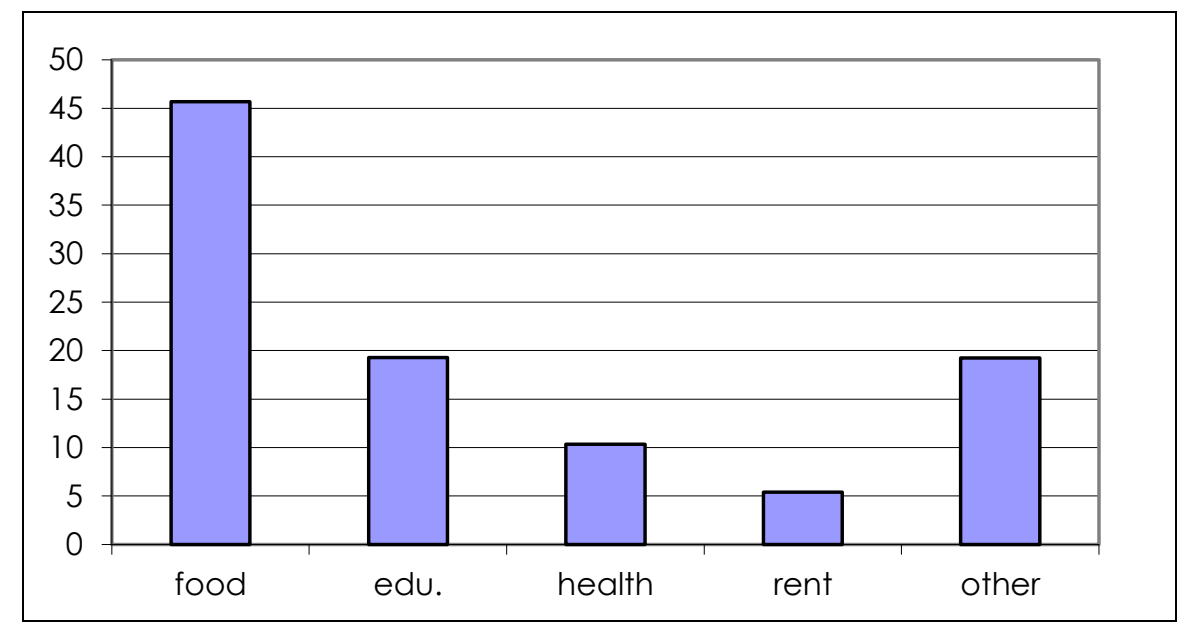

Figure 1 Left behind received remittance allocation

Source: Author's creation based on survey data.

The figure 1 shows the usage of the remittance received by migrants' left behinds. The survey revealed that $45.7 \%$ of the received remittance is used in food expenditure, $19.3 \%$ in education expenditure, $10.36 \%$ is used in health expenditure and $5.4 \%$ is allocated to house rent. The remaining of the remittance received is affected in other expenditure. Therefore, the survey results indicate that the remittances contribute to improve the living conditions of the left behind family.

The answers provided by the respondents to the question "Will you encourage another family member for migration?" is provided in the figure 2.

Figure 2 reveals that $56 \%$ of the respondents will not encourage family member for migration while $14 \%$ will encourage and the $30 \%$ are indifferent. The study further the investigation by assessing the correlation between the amount of the remittances sent by the migrant, the size of their family and the desire degree of the left behind 
to see another member of their family engage in migration. For this purpose, the migrants' left behind were asked to rank from 1 to 5 their desire degree to see another member of their family engage in migration, with 5 meaning a strong desire and 1 a low desire. The correlation test results are given in the table 11

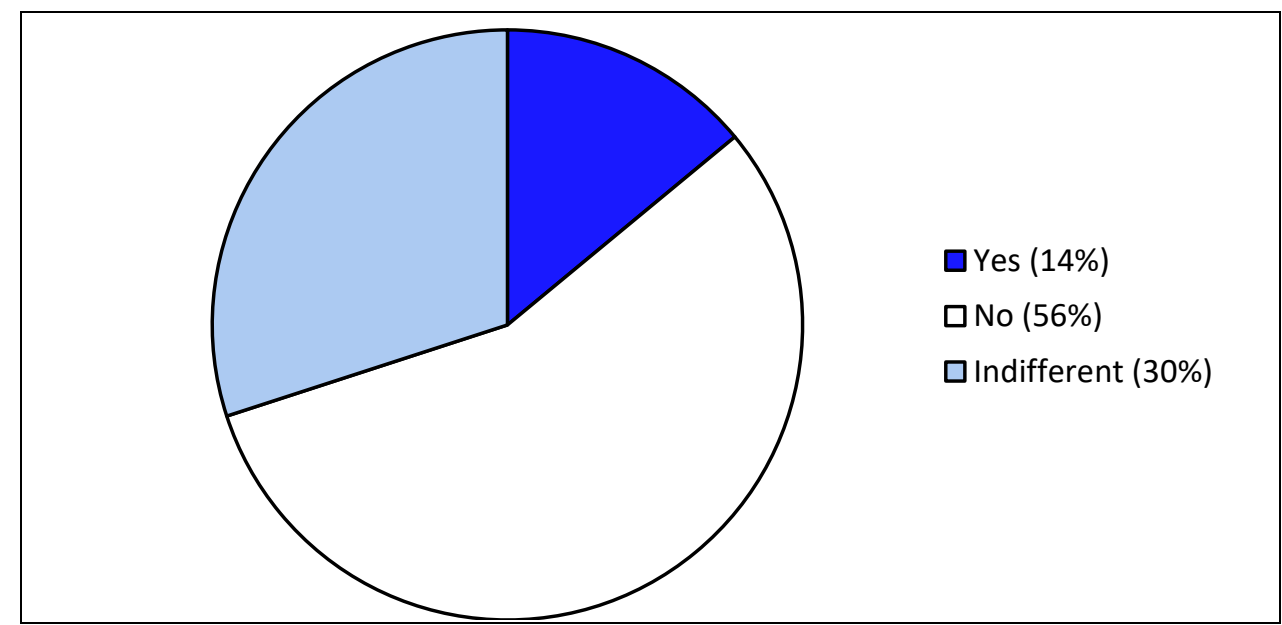

Figure 2 Respondents' answer regarding encouraging another family member for migration

Source: Author's calculation based on survey data.

Table 11 Migrants' received remittance, their family size and their desire degree correlation test results

\begin{tabular}{|c|c|c|c|}
\hline & remittance amount & family size & desire degree \\
\hline remittance amount & 1 & -0.023 & 0.754 \\
family size & -0.023 & 1 & 0.044 \\
desire degree & 0.754 & 0.044 & 1 \\
\hline
\end{tabular}

Source: Author's calculation based on data from the survey.

Table 11 indicates a significant correlation between the amount of remittance received by the migrants' left behind and their desire to see another family member engage in migration. The correlation test results also show no significant correlation between the amounts of remittance received by the migrants' left behind and the family size and finally no significant correlation between the family size and the desire to see another family member engage in migration.

\section{Conclusion}

Migration is a question of concern for both the country of origin and the destination country. Remittances sent by the migrants have long been an important source of revenue for many people around the world. The current study analyzes the effects of remittances on Niger economic growth and its contribution in improving the living condition of the migrants' left behind families in the city of Tahoua in Niger. For this analysis, the study employed various time series econometric techniques such as unit root test, Engle-Granger cointegration test, vector autoregressive (VAR) method and some diagnostic tests on the residuals. The empirical results showed no long run relationship between remittances, economic growth and Gross fixed capital formation in Niger. However, the study revealed the existence of causal effect between Remittances and Economic growth in the short-run. On the other hand, the results of the conducted survey in the city of Tahoua showed that $45.7 \%$ of the received remittance is used in food expenditure, $19.3 \%$ in education expenditure, 
$10.36 \%$ is used in health expenditure and $5.4 \%$ is allocated to house rent. The survey also revealed the importance of the remittances for the left behind. It indicates that $14 \%$ of the respondent left behind wish to see another family member engage in migration. The survey finally shows significant correlation between the amount of remittance received by the migrants' left behind and their desire to see another family member engage in migration.

The present research is important because of three main reasons: first, there are no previous studies investigating the relation between remittances and economic growth in Niger, second, the study provides empirical valuable information for policy makers in Niger on the impact of remittances on economic growth in Niger, third, the study provides valuable information on the impacts of migration on the migrants' left behind. The study recommends that policy makers in Niger make young Nigeriens aware of the difficulties of migration. The study finally recommends that policy makers provide financial support to young Nigeriens.

\section{References}

1. Adenutsi, E. D. (2010). Do international remittances promote human development in poor countries? Empirical evidence from Sub-Saharan Africa. The International Journal of applied economics and Finance, Vol. 4, No. 1, pp. 31-45.

2. Anetor, O. F. (2019). Remittance and economic growth nexus in Nigeria: Does financial sector development play a critical role? International Journal of Management, Economics and Social Sciences, Vol. 8, No. 2, pp. 116-135.

3. Annie, H. L., Nicole, S. (2018). Migration, Remittances and Human Capital Investment in Kenya. IZA Institute of labor economics.

4. Eric, K., Mohammad, S. (2019). A Note on the Long-Run Relationship between Growth and Remittances Using a Time Series Approach. Journal of Banking and Finance Management, Vol. 2, No. 2, pp. 6-18.

5. Hillel, R., Frédéric, D. R. (2004). Skilled Migration: The Perspective of Developing Countries. Policy Research Working Paper, No. 3382, pp. 1-39.

6. Juthathip, J., Archanun, K. (2019). Workers' Remittances, Capital Inflows and Economic Growth in Developing Asia and the Pacific. Asian Economic Journal, Vol. 3, No. 1, pp. 3950.

7. Manuel, O., Mariellen, J. (2019). The impact of migrants' remittances and investment on rural youth. IFAD, Rome.

8. Worldbank (2019). Migration and Remittances Data. Available at https://www.worldbank.org/en/topic/labormarkets/brief/migration-and-remittances [March 15, 2021].

\section{About the author}

Issoufou Oumarou is affiliated to the University of Tahoua/NIGER. He is PhD. in economics. He received the Ph.D. degree from the University of International Business and Economics (UIBE) in China in 2011. He received the 2011 Best Teaching Assistant award of the University of International Business and Economics. He was head of the Department of Economics and Management of the School of Law, Economics and Management of the University of Tahoua/NIGER from 2015 - 2019. He is affiliated to the Research and Analysis Laboratory on Economic and Social Development (LARADES). He teaches Macroeconomics, International economics and Finance. His main researches focus on economic growth, foreign direct investment, trade, remittances and public debt. He has published and co-authored several articles on economic growth in Niger and in the West African Economic and Monetary Union (WAEMU). The author's Orcid number is 0000-0002-7950-5612. The author can be contacted at oumar1911@yahoo.com. 